\title{
An Efficient Approach to Slicing Learning Video to Improve Learning Effectiveness by Considering Learner Prior Knowledge
}

\author{
Chien-I Lee ${ }^{1 *}$, Chang-Lin Tsai ${ }^{1}$ \\ ${ }^{1}$ National University of Tainan, Tainan, TAIWAN
}

Received 3 May 2017 - Revised 4 February 2018 • Accepted 13 February 2018

\begin{abstract}
Video has become a popular tool in today's instructional environment, which also imposes additional cognition load for learners, thereby sabotaging their learning performance. To address this problem, researchers have attempted to slice video into smaller segments, known as the "segmentation effect," so as to reduce learners' cognition load. Therefore, this paper proffers appropriate strategies with which to slice a learning video aimed at learners with different levels of prior knowledge. This is expected to reduce the cognition load of learners of differing levels, ultimately increasing their learning efficiency. This study chose its research subjects from a primary school in the southern part of Taiwan. A random sampling was conducted to create three classes for this experiment, one class with 32 students as the control group, whereas the other two classes all with 34 students as experimental group 1 and experimental group 2, respectively. Research results indicate that whether a learner is endowed with high-level, intermediate-level, or low-level prior knowledge, all participants in the experimental group outperformed their counterparts in the control group. The results cannot be inferred to other grades of students. In the future, this research will also be extended to other courses or disciplines.
\end{abstract}

Keywords: segmentation effect, expertise reversal effect, learning effectiveness

\section{INTRODUCTION}

Cutting-edge technology and widespread use of broadband networks enable us to easily interact with others wherever they are. Whether it be social sites like blogs and Facebook, or video-hosting websites like YouTube, websurfers can easily share their life experiences, ideas, or notes taken in the learning process, over the internet. Some researchers even upload their research ideas or academic resources, so individuals with an interest in that field of study may learn from each other over this platform. These multimedia resources benefit teachers and students alike by providing a massive repertoire and convenient avenues for exploration. For example, a step-by-step solution to a math problem can be shown on a video (Ertelt, Renkl, \& Spada, 2006). Video presents what is going on in the real world via audio/visual communications technologies (Paivio, 1986). This range of stimuli can strengthen learners' memories and impressions of the content while increasing their attention span. Moreover, the demonstrative effect rendered by video may help learners to reflect over the material at hand and enjoy the process of learning (Liu, Chen, \& Chang, 2010).

When viewers watch a video, they not only have to identify a series of scenes and images and quickly understand how the current scene is related to the previous ones, they also need to connect new knowledge to what is already known. This is a huge task for the short-term memory and one that increases cognition load for learners, whose learning performance may suffer as a result (Hasler, Kersten, \& Sweller, 2007; Spanjers, Van Gog, \& van Merriënboer, 2010). To reduce cognition load, Mayer and Moreno (2003) suggested that a video be broken up into a series of small segments so viewers can better absorb the information and try to integrate the previous and newly acquired knowledge on their own. They called this the "segmentation effect". When Kalyuga, Ayres, Chandler, and Sweller (2003) examined a range of instructional techniques designed to address learner experience and reduce cognitive load, they advised that certain techniques can induce expertise reversal effect. Simply put, in expertise

(c) 2018 by the authors; licensee Modestum Ltd., UK. This article is an open access article distributed under the terms and conditions of the Creative Commons Attribution License (http://creativecommons.org/licenses/by/4.0/). $\square$ leeci@mail.nutn.edu.tw (*Correspondence) $\square$ aa401402@gmail.com 


\section{Contribution of this paper to the literature}

- Both clustering technologies and concept mapping techniques are employed to break a video into several small pieces in order to accommodate the needs of learners with differing levels of prior knowledge and help them learn effectively.

- This study also prove that when teachers provide instructional video materials to their students, they need to take learners' prior knowledge, segmentation effect, and expertise reversal effect into account.

- This paper is the first research for primary school students by employing clustering technologies and concept mapping techniques in video segmentation, in order to examine how different strategies of segmentation help improve learner performance.

reversal the effect of instructional techniques correlates to learners' expertise in a reverse fashion. Scaffold instruction will likely lose its positive effect on more experienced learners, sometimes to the extent that learning performance is negatively affected (Dankbaar, Alsma, Jansen, van Merrienboer, van Saase, \& Schuit, 2016).

Research results indicate a negative correlation between instructional techniques and learners' domain knowledge and prior experience (Kalyuga, 2007, 2008; Leahy \& Sweller, 2005; Reisslein, Atkinson, Seeling \& Reisslein, 2006; Rey \& Buchwald, 2011). Specifically speaking, video segmentation proves little value to seasoned learners (Spanjers, van Gog, Wouters, \& van Merriënboer, 2012).

As expertise reversal effect tends to hinder the learning performance of experienced learners, it is necessary to determine an effective technique for the appropriate segmentation of instructional videos. In an effort to fill this gap, the present study examined a set of videos and asked participants to answer questions related to their prior knowledge. We then implemented clustering technologies (Xiaojun, 2017) to segment the videos. Although clustering technologies help save a lot of time and manpower in the video segmentation process, they might not be good at identifying explicit learning concepts.

Novak and Gowin (1984) proposed strategies to construct concept maps based on the assimilation theory developed by Ausubel, Novak and Hanesian in 1968. This theory stresses that prior knowledge helps learners comprehend a new concept and build a cognition relationship between old and new ideas. The technique of concept mapping can be used to help learners gain knowledge through their own current cognition structure, and further connect new cognition structure to previously built ones. According to Novak, a concept map helps students better express their comprehension and grasp the locus of thought. Through the visualization of relationships among different concepts, learners are able to organize information via a diagram that graphically depicts the relationships among concepts (Novak, 1990). Hence this study further employed the technique of concept mapping to discover participants' prior knowledge and to more accurately segment videos so as to accommodate the needs of novice and seasoned learners simultaneously (Hilbert \& Renkl, 2009; Scheiter, Fillisch, Krebs, Leber, Ploetzner, Renkl, \& Zimmermann, 2017; Soellner, Lenartz, \& Rudinger, 2017).

With the research background and motivations in mind, this study employed three video segmentation strategies: undifferentiated video segmentation, video segmentation using clustering technologies, and video segmentation using concept mapping. Each student was given video clips that best suit their needs.

\section{Research Question}

The specific research questions that guided this study are as follows:

(1) How do the aforementioned three strategies affect learner performance?

(2) How do the aforementioned three strategies affect learners with different levels of prior knowledge?

\section{Research Hypothesis}

Based on the research questions, the hypotheses of this study are as follows:

(1) Learners were provided with a video that was sliced using concept mapping techniques have better learning effectiveness than those with undifferentiated video segmentation and those with a video that was sliced using clustering technologies.

(2) Learners with high-level prior knowledge have not significant difference in learning effectiveness when exposed to aforementioned three strategies. On the other hand, learners with intermediate-level and lowlevel learners would have significant improvement in learning when exposed to the video trimmed using concept mapping techniques. 


\section{THEORETICAL FRAMEWORK}

Mayer and Chandler (2001) conducted an experiment on college students to determine whether the segmentation of videos has an influence on learning outcomes. Results showed that participants who viewed a segmented video had a higher score in the "problem-solving and transfer" test than their counterparts (Mayer, 1997; Mayer \& Chandler, 2001). Later, Mayer and Moreno (2003) presented a principle of instruction known as the "segmentation effect," which advocates slicing a teaching material (as a video) into manageable pieces, so that learners have time to absorb the information at hand, one step at a time. This improves learners' autonomy in setting a pace for themselves so all learners, whether they have sufficient prior knowledge or not, will succeed in their studies (Mayer \& Chandler, 2001; Mayer \& Moreno, 2003).

The reason why segmentation works wonders for learners may be because it reduces the cognition load on learners, especially novices who have difficulty in memorizing quickly passing information. It helps to fixate the attention of viewers on the video, by adding cut points at intervals. This way, learners are better able to understand ideas and process them into their knowledge frameworks. Meanwhile, cut points, like a temporal cueing, may help relieve stress and save cognition resources in processing information, as they function as boundaries between events. For a unit of instruction, temporal cueing suggests an embedded structure in instructional materials, so learners may learn something new in a more organized way (Spanjers et al., 2010; Spanjers, van Gog, Wouters, \& van Merriënboer, 2011).

Furthermore, a learner's professional knowledge is key to her/his attitude and reception of certain messages or knowledge. Higher-knowledge learners (also called experts) are equipped with many schemas of domain knowledge. Their stratified structure of knowledge lends itself to an advanced schema, which is produced from organization of multiple elements of certain knowledge (Carpenter, Lund, Coffman, Armstrong, Lamm, \& Reason, 2016). This advanced schema is regarded as a single unit. When faced with elements of knowledge, experts know how to effectively employ them as working memory. These higher-level elements or units consume far less working memory resources than disorganized low-level elements. In other words, schemas are at experts' disposal to handle massive amounts of information and then reduce working memory load. In addition, schema automation relieves the constraints on working memory for experts, so they can use as few resources as possible to resolve a problem (Kalyuga, 2005, 2007; Kalyuga \& Sweller, 2004).

Learners' acquisition of domain knowledge therefore determines how they integrate current and previous information using established schemas held in working memory. Novice learners do not master schemas that can help them solve problems or fulfil the task at hand. It follows that instructional designs that are scaffolded may help novices build schemas in processing new ideas. When an instructional design fails to provide structural guidance for learners, these learners must rely on lower-level elements for cues in finding possible solutions and will inevitably have to wrestle with heavy working memory load (Boucheix \& Forestier, 2017).

To address this problem, the current study formulates three types of segmentation strategies: undifferentiated video segmentation, video segmentation using clustering technologies, and video segmentation using concept mapping. In this experiment, the independent variable is the type of segmentation; the control variables are instructional content and level of prior knowledge; the dependent variable is the performance of the learner in the post-test; and the covariate variable is the pre-test taken by a learner before she/he watches a segmented video. Variables are considered in more detail below:

(1) Independent variables:

(a) Undifferentiated video segmentation:

All participants were exposed to the same video segmented according to the same technique.

(b) Experimental group 1:

Learners were split into three groups based on their level of prior knowledge (measured by a pre-test) and then provided with a video that was segmented using clustering technologies.

(c) Experimental group 2:

Learners were split into three groups based on their level of prior knowledge (measured by a pre-test) and then provided with a video that was sliced using concept mapping techniques.

(2) Dependent variables

Learning outcomes: All three groups took a post-test to see what they had learned during the experimental activity. 
Table 1. The number of students of different levels of prior knowledge

\begin{tabular}{lccc}
\hline Group & Control group & Experiment group 1 & Experiment group 2 \\
\hline High-level & 10 & 10 & 10 \\
\hline Intermediate-level & 13 & 14 & 14 \\
\hline Low-level & 9 & 12 & 10 \\
\hline
\end{tabular}

(3) Control variables:

(a) Instructional content:

The 5th-grade mathematics unit focusing on "Four Fundamental Operations of Arithmetic" was used as the teaching material.

(b) Test of prior knowledge:

A test was carried out among participants to determine their prior knowledge.

(c) All of the groups were taught by the same teacher.

(4) Covariate variable:

Pre-test: A pre-test and post-test were carried out in all three groups in order to examine differences in learning performance before and after the experiment.

\section{METHODOLOGY}

\section{Research Framework and Participants}

This study adopted a quasi-experimental design with one designated experimental group and two control groups comprising students. Taking time/manpower constraints and investigative and administrative procedures into consideration, this study chose its research subjects from a primary school in the urban area in the southern part of Taiwan. All were fifth graders and placed in a class of mixed ability. A random sampling was conducted to create three classes for this experiment. One class was designated as the "control group," whereas the other two classes were "experimental group 1" and "experimental group 2". Before the video-watching activity, a pre-test was carried out to measure prior knowledge regarding the learning material. An independent-sample t-test was used to analyze scores of the pre-test. No significant difference was detected among the three groups. Among them, the 32 pupils in the control group were supplied with a video using undifferentiated segmentation. The 36 participants in experimental group 1 were provided with a video that was trimmed using clustering technologies, whereas the 34 participants in experimental group 2 watched a video that was sliced into smaller pieces using concept mapping techniques. Additionally, the above three groups were each divided up into high-, intermediate, and low-level knowledge types of learners. Details are shown in Table 1.

\section{Research Tools}

\section{An online video platform}

This video platform was built by the authors using PHP Hypertext Preprocessor coupled with MySQL Database. Users need to $\log$ in to the system and fill in personal information before registering as a member. Then they are given a learning video segmented according to their pre-test scores (shown in Figure 1). Users press any key for the video to continue from cut points, placing control of the pace of learning in their hands (Figure 2). 


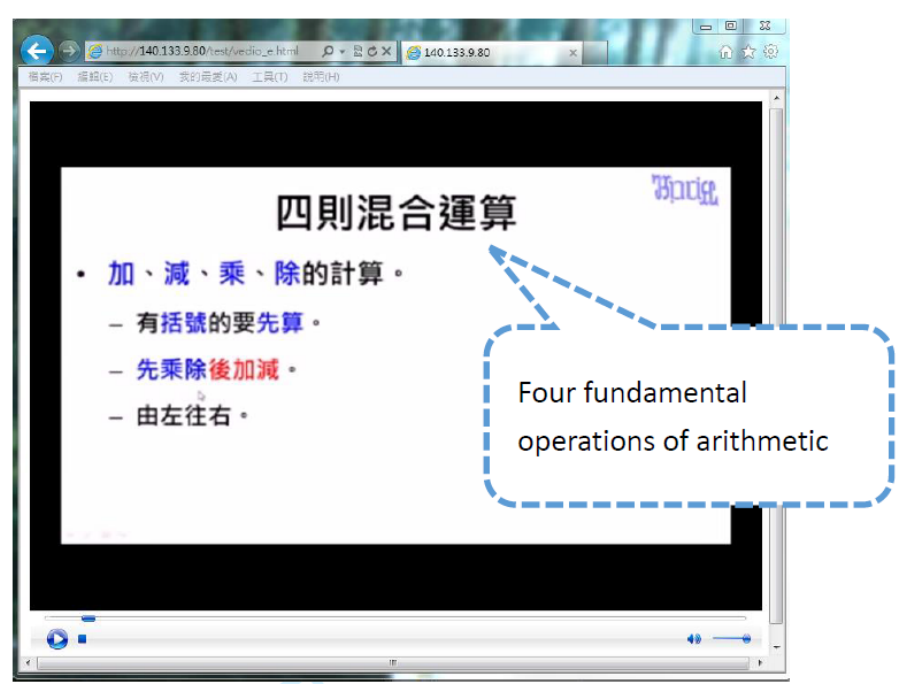

Figure 1. Screenshot of the video playback system

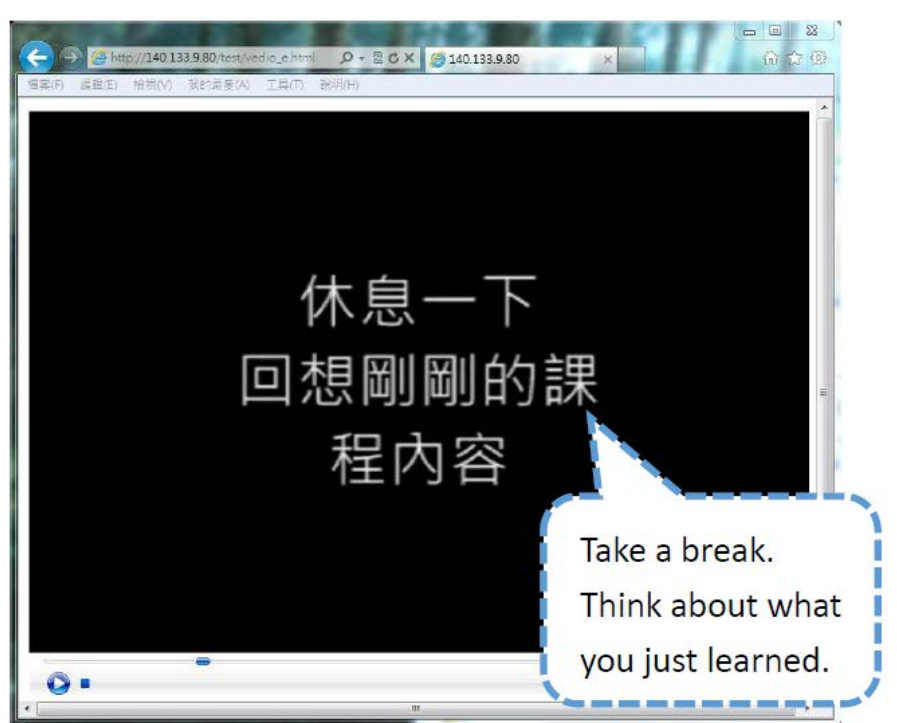

Figure 2. Screenshot of the cut point

Table 2. Two-way specification table of pre-test questions

\begin{tabular}{lccccc}
\hline Teaching objectives & Knowledge & Comprehension & Application & Analysis & Sum \\
\hline Four fundamental operations of arithmetic & 4 & 1 & 3 & 1 & 9 \\
\hline Distribution law & 0 & 2 & 2 & 2 & 6 \\
\hline Sum & 4 & 3 & 5 & 3 & 15 \\
\hline
\end{tabular}

\section{Test items of pre- and post-test}

The items in both pre- and post-tests were devised by five math teachers, each with over ten years' experience. The two-way specification table is presented in Table 2, which was drawn up in accordance with the taxonomy of cognition development developed by Bloom: knowledge, comprehension, application and analysis (Bloom, 1956). Of these test items, 4 were designed for knowledge, 3 for comprehension, 5 for application, and 5 for analysis.

As the results of pre-test analysis shown in Table 3, item discrimination was measured via the correct rate of the high-score minus the correct rate of low-score groups. Item difficulty analysis was measured by adding the two correct rates and then dividing them. The sample comprised 46 pupils, who were chosen from two classes of a primary school in southern Taiwan. The top and bottom $27 \%$ were categorized as the high-score and low-score groups, respectively. Lastly, the criteria for item difficulty and item discrimination was set between 0.2 and 0.8 , and below 0.3 , respectively. The item difficulty and item discrimination of Item 5 were 0.94 and 0.13 , which was not a 
Table 3. The result of pre-test analysis

\begin{tabular}{ccccc}
\hline Item & $\begin{array}{c}\text { The correct rate of } \\
\text { High-score groups }\end{array}$ & $\begin{array}{c}\text { The correct rate of } \\
\text { Low-score groups }\end{array}$ & $\begin{array}{c}\text { Item } \\
\text { difficulty }\end{array}$ & $\begin{array}{c}\text { Item } \\
\text { discrimination }\end{array}$ \\
\hline 1 & 0.93 & 0.10 & 0.52 & 0.83 \\
\hline 2 & 0.96 & 0.20 & 0.58 & 0.76 \\
\hline 3 & 0.93 & 0.27 & 0.60 & 0.66 \\
\hline 4 & 0.87 & 0.03 & 0.45 & 0.84 \\
\hline 5 & 1.00 & 0.87 & 0.94 & 0.13 \\
\hline 6 & 1.00 & 0.37 & 0.69 & 0.63 \\
\hline 7 & 0.97 & 0.53 & 0.75 & 0.44 \\
\hline 8 & 0.97 & 0.17 & 0.57 & 0.80 \\
\hline 9 & 0.93 & 0.57 & 0.75 & 0.36 \\
\hline 10 & 1.00 & 0.60 & 0.80 & 0.40 \\
\hline 11 & 1.00 & 0.57 & 0.79 & 0.43 \\
\hline 12 & 0.97 & 0.60 & 0.79 & 0.37 \\
\hline 13 & 0.97 & 0.43 & 0.70 & 0.54 \\
\hline 14 & 0.97 & 0.43 & 0.70 & 0.54 \\
\hline 15 & 0.90 & 0.20 & 0.55 & 0.70 \\
\hline
\end{tabular}

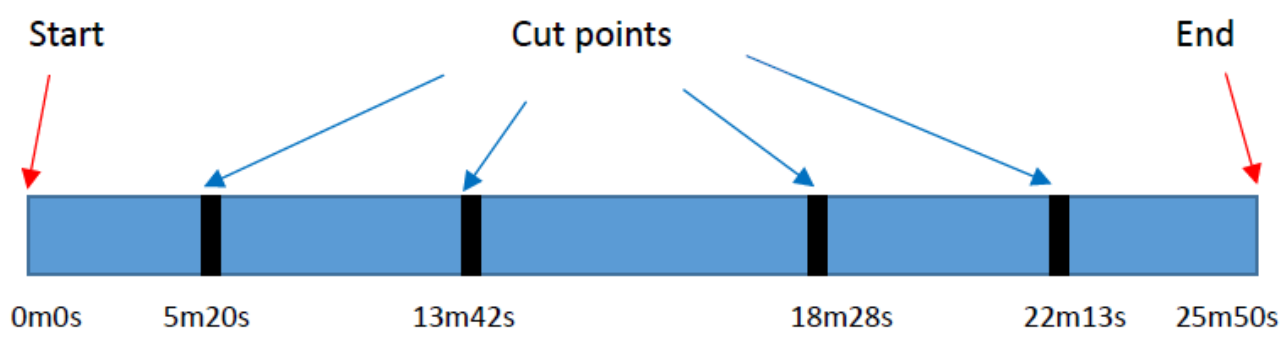

Figure 3. The result of pre-test analysis

proper question. Item 5 needed to be revised to meet the above criteria. After revision, the reliability of the pre-test is 0.810 (>0.7), demonstrating good reliability.

After the experiment, all students (from two experimental groups and one control group) were asked to take a post-test in order to gauge the participants' learning performance during the experiment. After the validity of the post-test was confirmed, item difficulty and item discrimination were analyzed to decide if any items should be revised. The criteria for such revisions were identical to those of the pre-test, and were later used as guidelines for test optimization. The sample (of 44 pupils) was also taken from two another classes of a primary school in southern Taiwan. The post-test's reliability reaches $0.832(>0.7)$, demonstrating good reliability.

\section{Experimental Design and Procedures}

The 3-stage experiment was conducted as follows:

(1) Pre-test: A pre-test was carried out in all groups (one control group and two experimental groups) to measure the level of their prior knowledge.

(2) Learning activity: This activity was divided into two steps:

(a) On the day of the experiment, an explanation and demonstration were provided for the learners to teach them how to operate the video player interface.

(b) Users were engaged in video learning activity.

(3) Post-test: A post-test was carried out among all participants after the video learning activity was over.

Participants were shown an animated video focusing on step-by-step solutions to math problems. For the control group and experimental group 1, the video lasted 25 mins and 50 secs. For experimental group 2, the video lasted 44 mins and 16 secs. This period was interspersed with a lot of cut points. The number and positions of cut points varied according to the participants' prior knowledge.

Figure 3 presents a flow chart of the video watching activity designed for the control group. All participants, regardless of their level of prior knowledge as determined by the pre-test, were presented with the video with identical length and positions of cut points. 
There were 2 cut points of video for high-level prior knowledge students

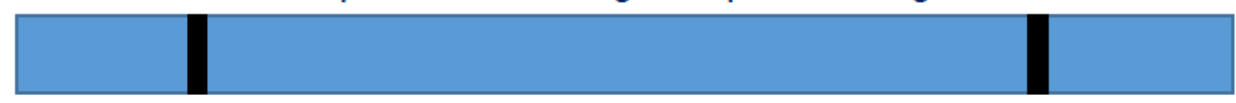

There were 3 cut points of video for intermediate-level prior knowledge students

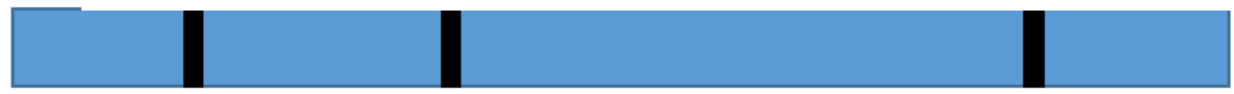

There were 4 cut points of video for low-level prior knowledge students

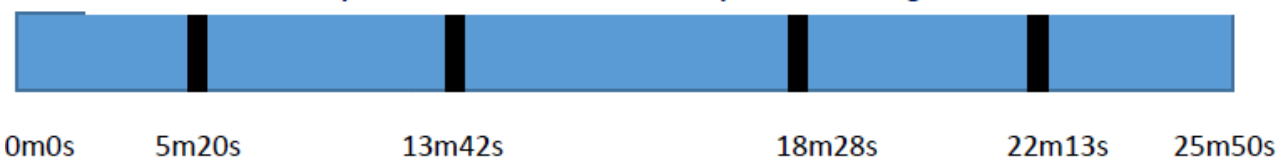

Figure 4. The process of video watching activity in experiment group 1

There were 2 cut points of video for high-level prior knowledge students

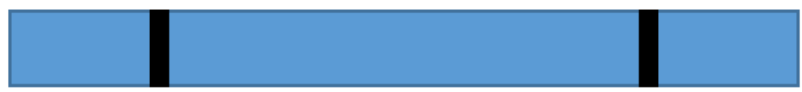

There were at most 7 cut points of video for each intermediate-level or low-level prior knowledge student according to his/her pre-test score

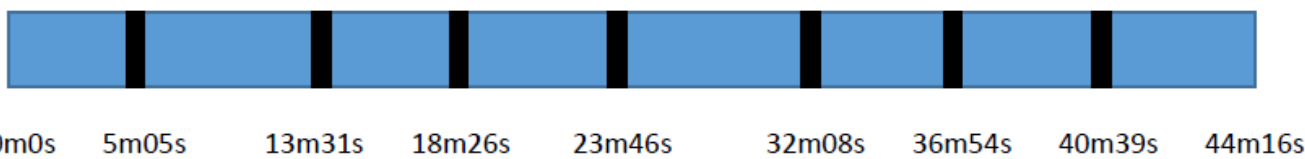

Figure 5. The process of video watching activity in experiment group 2

In Figure 4, there is a flow chart of the video watching activity designed for experimental group 1. Participants were split into three groups based on their pre-test results, and each group was presented with a video that was sliced at different positions according to the viewer's level of prior knowledge. For those with high-level prior knowledge, two cut points were set at $5^{\prime} 20^{\prime \prime}$ and $22^{\prime} 13^{\prime \prime}$. For those with intermediate-level prior knowledge, three cut points were set at $5^{\prime} 20^{\prime \prime}, 13^{\prime} 42^{\prime \prime}$, and $22^{\prime} 13^{\prime \prime}$. For those with low-level prior knowledge, four cut points were set at $5^{\prime} 20^{\prime \prime}, 13^{\prime} 42^{\prime \prime}, 18^{\prime} 28^{\prime \prime}$, and $22^{\prime} 13^{\prime \prime}$. The cut points of video for each group were carefully determined by the teachers with their teaching experiences of "Four Fundamental Operations of Arithmetic" according to the prior knowledge of these three groups, respectively. Basically, the lower the prior knowledge, the more cut points were set.

Figure 5 shows a flow chart of the video watching activity designed for experimental group 2. As shown in Figure 6, the concept map was used to trim the video by the teacher previously. Participants were split into three groups based on their pre-test results, and each group was presented with a video that was cut at different positions according to the viewer's level of prior knowledge. For those with high-level prior knowledge, two cut points were set at $5^{\prime} 20^{\prime \prime}$ and $22^{\prime} 13^{\prime \prime}$. For those with intermediate-level prior knowledge, three cut points were set at $5^{\prime} 20^{\prime \prime}, 13^{\prime} 42^{\prime \prime}$, and $22^{\prime} 13^{\prime \prime}$. For those with low-level prior knowledge, four cut points were set at $5^{\prime} 20^{\prime \prime}, 13^{\prime} 42^{\prime \prime}, 18^{\prime} 28^{\prime \prime}$, and $22^{\prime} 13^{\prime \prime}$. In addition to an animated video focusing on step-by-step solutions to math problems, other videos focusing on similar concepts were provided as well. For learners with high-level prior knowledge, two cut points were set at 5'20' and 22'13'. The intermediate- and low-level groups were shown different videos focusing on feature similar concepts before watching the target video. The maximum number of cut points was 7 points at $5^{\prime} 05^{\prime \prime}, 13^{\prime} 31^{\prime \prime}, 18^{\prime} 26^{\prime \prime}$, $23^{\prime} 46^{\prime \prime}, 32^{\prime} 08^{\prime \prime}, 36^{\prime} 54^{\prime \prime}$, and 40'39". 


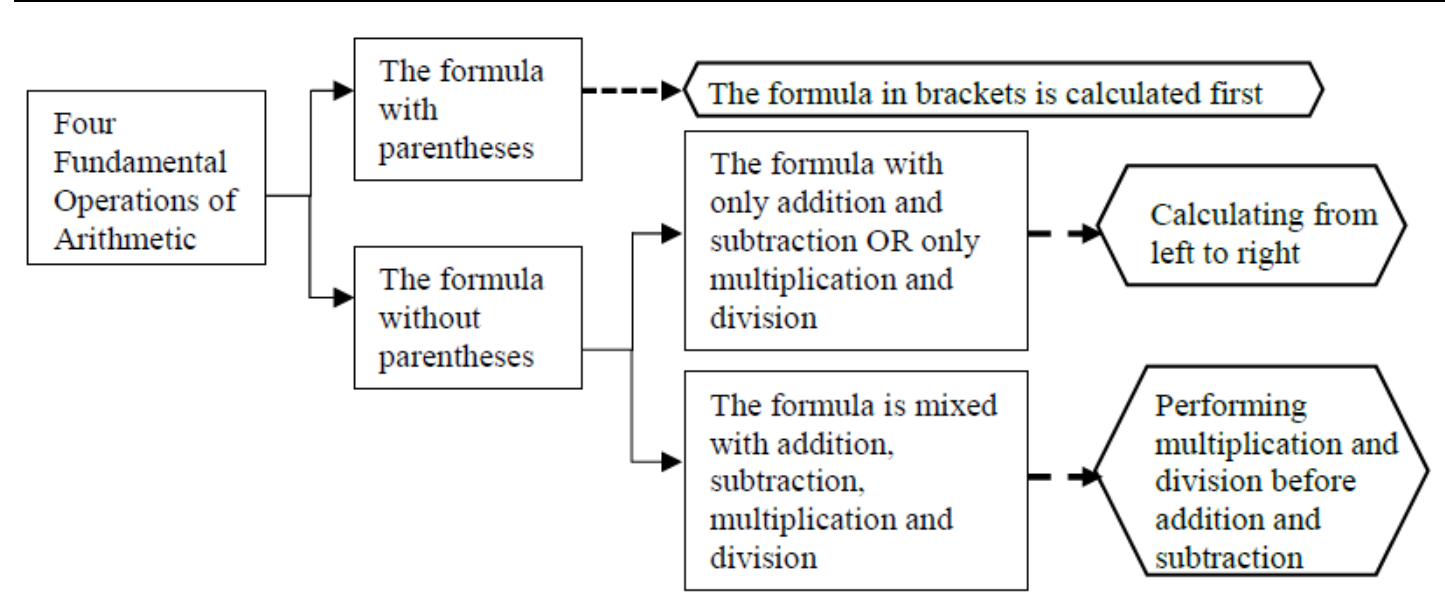

Figure 6. The concept map of "Four Fundamental Operations of Arithmetic"

Table 4. Paired samples t-test results of the pre-test and post-test within control group

\begin{tabular}{lllll}
\hline & $\mathbf{N}$ & $\mathbf{M}$ & SD & $\mathbf{p}$ \\
\hline Pre-test & 32 & 71.19 & 20.287 & \multirow{2}{*}{$.002^{* *}$} \\
\hline Post-test & 32 & 85.69 & 15.782 & \\
\hline${ }^{*} \mathrm{p}<.05^{* \star} \mathrm{p}<.01$ & & & &
\end{tabular}

${ }^{*} \mathrm{p}<.05{ }^{* \star} \mathrm{p}<.01$

Table 5. Paired samples t-test results of the pre-test and post-test within experiment group 1

\begin{tabular}{lllll}
\hline & $\mathbf{N}$ & $\mathbf{M}$ & $\mathbf{S D}$ & $\mathbf{p}$ \\
\hline Pre-test & 36 & 66.00 & 26.679 & \multirow{2}{*}{$.000^{* * *}$} \\
\hline Post-test & 36 & 81.33 & 24.699 & \\
\hline${ }^{*} \mathrm{p}<05^{* \star} \mathrm{p}<.01^{* * *} \mathrm{p}<001$ & & &
\end{tabular}

Table 6. Paired samples t-test results of the pre-test and post-test within experiment group 2

\begin{tabular}{lllll}
\hline & $\mathbf{N}$ & $\mathbf{M}$ & $\mathbf{S D}$ & $\mathbf{p}$ \\
\hline Pre-test & 34 & 66.65 & 22.871 & \multirow{2}{*}{$.000^{* * *}$} \\
\hline Post-test & 34 & 82.41 & 26.029 & \\
\hline${ }^{*} \mathrm{p}^{*} 05^{* *} \mathrm{p}<01^{* \star *} \mathrm{p}<001$ & & &
\end{tabular}

Table 7. ANCOVA analysis of learning effectiveness between control group and experiment group 1

\begin{tabular}{lllll}
\hline & $\mathbf{N}$ & $\mathbf{M}$ & SD & F \\
\hline Control group & 32 & 85.69 & 15.782 & \multirow{2}{*}{2.257} \\
\hline Experiment group 1 & 36 & 81.33 & 20.946 & \\
\hline
\end{tabular}

\section{RESULTS}

\section{Analysis of Pre- and Post-tests}

All three groups of participants were provided with pre-and-after tests; therefore we performed a paired sample t-test to compare learning performances. Table 4 demonstrates that the control group received an average score of 85.69 in the post-test, significantly higher than 71.19 of the pre-test $(t=-4.608, p<0.01)$. Similarly, experimental group 1 (clustering technology) obtained an average score of 81.33 in the post-test, significantly higher than 66.00 in the pre-test $(\mathrm{t}=-4.364, \mathrm{p}<0.001)$, shown in Table 5. Table 6 shows that experimental group 2 (concept mapping technique) obtained an average score of 82.41 in the post-test, significantly higher than 66.65 of the pre-test $(\mathrm{t}=$ 4.727, $\mathrm{p}<0.001$ ). In all three groups, the score of the post-test in learning performance was significantly higher than that of the pre-test.

\section{Analysis of Influence of Video Segmentation on Learning Outcomes}

We performed ANCOVA to verify whether undifferentiated video segmentation, video segmentation using clustering technologies, and video segmentation using concept mapping technique, would exhibit different learning outcomes in pairs of comparison. Results are shown in Tables 7, 8, and 9. 
Table 8. ANCOVA analysis of learning effectiveness between control group and experiment group 2

\begin{tabular}{lcccc}
\hline & N & M & SD & F \\
\hline Control group & 32 & 85.69 & 15.782 & \multirow{2}{*}{2.619} \\
\hline Experiment group 2 & 34 & 82.41 & 26.029 & \\
\hline
\end{tabular}

Table 9. ANCOVA analysis of learning effectiveness between experiment group 1 and experiment group 2

\begin{tabular}{lllll}
\hline & $\mathbf{N}$ & $\mathbf{M}$ & SD & F \\
\hline Experiment group 1 & 36 & 81.33 & 20.946 & \multirow{2}{*}{.001} \\
\hline Experiment group 2 & 34 & 82.41 & 26.029 & \\
\hline
\end{tabular}

Table 10. Paired samples t-test results of the pre-test and post-test of different levels of prior knowledge within control group

\begin{tabular}{|c|c|c|c|c|c|}
\hline Level & & $\mathbf{N}$ & $\mathbf{M}$ & SD & p \\
\hline \multirow{2}{*}{ High-level } & pre-test & 10 & 95.60 & 5.060 & \multirow[b]{2}{*}{.653} \\
\hline & post-test & 10 & 94.80 & 5.514 & \\
\hline \multirow{2}{*}{ Intermediate-level } & pre-test & 13 & 69.85 & 7.894 & \multirow{2}{*}{$.004^{* *}$} \\
\hline & post-test & 13 & 83.69 & 18.273 & \\
\hline \multirow{2}{*}{ Low-level } & pre-test & 9 & 46.00 & 46.00 & \multirow{2}{*}{$.000^{\star \star \star}$} \\
\hline & post-test & 9 & 78.44 & 16.149 & \\
\hline
\end{tabular}

${ }^{*} p<.05^{* *} p<.01^{* * *} p<.001$

Table 11. Paired samples t-test results of the pre-test and post-test of different levels of prior knowledge within experiment group 1

\begin{tabular}{|c|c|c|c|c|c|}
\hline Level & & $\mathbf{N}$ & $\mathbf{M}$ & SD & $\mathbf{p}$ \\
\hline \multirow{2}{*}{ High-level } & pre-test & 12 & 96.00 & 5.326 & \multirow{2}{*}{1.000} \\
\hline & post-test & 12 & 96.00 & 5.326 & \\
\hline \multirow{2}{*}{ Intermediate-level } & pre-test & 14 & 64.29 & 9.343 & \multirow{2}{*}{$.006^{\star *}$} \\
\hline & post-test & 14 & 85.43 & 21.661 & \\
\hline \multirow{2}{*}{ Low-level } & pre-test & 10 & 32.40 & 12.176 & \multirow{2}{*}{$.002^{\star * *}$} \\
\hline & post-test & 10 & 58.00 & 27.244 & \\
\hline
\end{tabular}

${ }^{*} p<.05^{* \star} p<.01{ }^{* * *} p<.001$

In Table 7, the output of ANCOVA $(\mathrm{F}(1,62)=2.257, \mathrm{p}>.05)$ reveals a non-significant difference between the control group and experimental group 1. In Table 8, the output of ANCOVA $(\mathrm{F}=2.619, \mathrm{p}>.05)$ reveals a nonsignificant difference between the control group and experimental group 2. Table 9 also shows a corresponding result in the learning outcomes of experimental group 1 and experimental group 2 ( $\mathrm{F}=.001, \mathrm{p}>.05)$.

To explore why different strategies of segmentation did not have a significant impact on learners, this study performed a paired sample t-test on the pre- and post-tests undertaken by high-, intermediate-, and low-level learners of the aforementioned three groups.

\section{Control group: undifferentiated video segmentation}

Table 10 shows the learning outcomes of high-level learners before and after watching the undifferentiated segmented video. The pre-test confirmed that these learners already had some understanding of step-by-step solutions to math problems. When they were engaged in the video learning activity, cut points (temporal cueing) seemed unnecessary for them because these pauses interfered with their learning process. Learners with intermediate- and low-level knowledge obtained higher scores in the post-test than in the pre-test. While both showed significant difference in their learning performance, the difference in low-level learners was more significant $(\mathrm{p}<0.001)$.

\section{Experimental group 1: segmentation using clustering technology}

Table 11 reveals the three levels of learners' outcomes produced before and after watching the video trimmed using clustering technologies. The data reveals that high-level learners were not significantly affected by this video using clustering technologies, which might be because they have already have a knack for acquiring new knowledge. On the other hand, intermediate- and low-level learners obtained a significantly higher score in their post-test. The significant levels were $<0.01$. Therefore segmentation through clustering technologies helped increase the learning performance of intermediate- and low-level participants. 
Table 12. Paired samples t-test results of the pre-test and post-test of different levels of prior knowledge within experiment group 2

\begin{tabular}{llllll}
\hline Level & & $\mathbf{N}$ & $\mathbf{M}$ & SD & P \\
\hline \multirow{2}{*}{ High-level } & pre-test & 10 & 94.00 & 6.864 & 9.046 \\
\hline \multirow{2}{*}{ Intermediate-level } & post-test & 10 & 94.60 & 6.157 & 19.732 \\
\hline \multirow{2}{*}{ Low-level } & pre-test & 14 & 66.71 & 12.155 & $.000^{\star *}$ \\
\cline { 2 - 5 } & pre-test & 14 & 89.14 & 39.20 & 32.947 \\
\hline
\end{tabular}

${ }^{*} p<.05^{* \star} p<.01^{* \star *} p<.001$

\section{Experimental group 2: segmentation using concept mapping technique}

Table 12 shows the three levels of learners' outcomes produced before and after watching the video trimmed using concept mapping techniques. According to the data, high-level learners showed a slightly higher score in the post-test than the pre-test, yet the t-test result exhibited little difference. This might be because learners with highlevel prior knowledge are skilled at integrating new material, and are not subject to outside influences. Intermediate-level learners, however, scored significantly higher in the post-test $(p<0.001)$. This was presumed to be because learners of this group benefitted from the video using concept mapping techniques, and have a fuller understanding of relevant ideas, thereby achieving efficiency in learning. Low-level learners obtained higher scores in the post-test after watching the video trimmed using concept mapping techniques. However, the significance level $(p<0.05)$ was lower than the undifferentiated and clustering technology groups. It was inferred to be due to the excessive length of this video, which caused an attention problem. Secondly, this might be because these lowlevel learners did not have adequate command of concepts before watching this video, and had difficulty in comprehending the content of this video.

The above analytical results validate that the three types of learners benefit from different methods of video segmentation. Learners with high-level prior knowledge did not show significant difference in learning performance when exposed to three differently segmented videos. Intermediate-level learners showed significant improvement in learning when exposed to the video trimmed using concept mapping techniques. Low-level learners made significant progress after watching the videos trimmed with undifferentiated segmentation and clustering technologies.

\section{DISCUSSION AND CONCLUSION}

Segmentation has a significant influence on learner performance. Previous studies investigated segmentation in which cut points were manually controlled by users; this study is the first to employ clustering technologies and concept mapping techniques in video segmentation, in order to examine how different strategies of segmentation help improve learner performance. Results validate the existence of segmentation effect. Additionally, the research hypothesis (1) is valid, that is, learners were provided with a video that was sliced using concept mapping techniques have better learning effectiveness than those with undifferentiated video segmentation and those with a video that was sliced using clustering technologies. Besides, learners with intermediate-level and low-level learners would have significant improvement in learning when exposed to the video trimmed using concept mapping techniques, but, learners with high-level prior knowledge have not significant difference in learning effectiveness when exposed to aforementioned three strategies.

Moreover, the research hypothesis (2) is also valid, it was revealed that high-level learners did not show significant improvement in their learning outcomes. More surprisingly, when high-level learners were exposed to a video with undifferentiated segmentation, a reverse effect was found in their learning outcomes, which validate the existence of expertise reversal effect (Chen, Kalyuga \& Sweller, 2017).

Even though different types of learners might benefit from different strategies of video segmentation and show improvement in their learning outcomes, it is worth noting that the intermediate-level learners who watched a video using concept mapping technique performed much better than their counterparts watching a video trimmed with clustering technologies. The instructor of the concept mapping group needed to spend additional time reviewing relevant concepts in that field of knowledge and checking cut points. Conversely, although the intermediate-and low-level learners watching a video using clustering technology did not show significant improvement, the instructor of that group was not required to spend extra time reviewing an array of concepts and checking cut points. Hence the two strategies of video segmentation, clustering vs. concept mapping, each have their own advantages and disadvantages. Instructor and learner attributes must be considered in the selection of the method most appropriate for the target audience (Blayney, Kalyuga \& Sweller, 2016). 


\section{RESEARCH LIMITATION AND FURTHER RECOMMENDATION}

Due to the limitation of experimental time and teaching environment, all participates in this study were fifth graders from a primary school in the urban area in the southern part of Taiwan. The results of this study cannot be inferred to other grades of students.

Besides, an instructor needs to take learners' prior knowledge, segmentation effect, and expertise reversal effect into account when she/he provides instructional video materials. Clustering technologies have a relatively modest effect on learner performance, yet this strategy is less time-consuming. Conversely, the concept mapping technique remarkably increases learner performance, yet it requires high investment from the teacher. In the future, more data mining technologies (Han, Kamber, \& Pei, 2011) would be applied in the development of the segmentation strategy during the learning process, which could automatically analyze and then segment video for an individual learner more effectively and efficiently aid in the improvement of learning performance.

\section{REFERENCES}

Ausubel, D. P., Novak, J. D., \& Hanesian, H. (1968). Educational psychology: A cognitive view. New York: Holt, Rinehart and Winston.

Blayney, P., Kalyuga, S., \& Sweller, J. (2016). The impact of complexity on the expertise reversal effect: experimental evidence from testing accounting students. Educational Psychology, 36(10), 1868-1885. https:/ / doi.org/10.1080/01443410.2015.1051949

Bloom, B. S., (Ed.). (1956). Taxonomy of educational objectives: The classification of educational goals: Handbook I, cognitive domain. New York: Longman.

Boucheix, J. M., \& Forestier, C. (2017). Reducing the transience effect of animations does not (always) lead to better performance in children learning a complex hand procedure. Computers in Human Behavior, 69, 358-370. https:// doi.org/10.1016/j.chb.2016.12.029

Carpenter, S. K., Lund, T. J., Coffman, C. R., Armstrong, P. I., Lamm, M. H., \& Reason, R. D. (2016). A classroom study on the relationship between student achievement and retrieval-enhanced learning. Educational Psychology Review, 28(2), 353-375. https:/ / doi.org/10.1007/s10648-015-9311-9

Chen, O., Kalyuga, S., \& Sweller, J. (2017). The expertise reversal effect is a variant of the more general element interactivity effect. Educational Psychology Review, 29(2), 393-405. https:/ / doi.org/10.1007/s10648-016-93591

Dankbaar, M. E., Alsma, J., Jansen, E. E., van Merrienboer, J. J., van Saase, J. L., \& Schuit, S. C. (2016). An experimental study on the effects of a simulation game on students' clinical cognitive skills and motivation. Advances in Health Sciences Education, 21(3), 505-521. https:/ / doi.org/10.1007/s10459-015-9641-x

Ertelt, A., Renkl, A., \& Spada, H. (2006). Making a difference: exploiting the full potential of instructionally designed on-screen videos. In Proceedings of the 7th International Conference on Learning Sciences, 154-160.

Han, J., Kamber, M., \& Pei, J. (2011). Data mining: concepts and techniques (3rd ed.). Burlington, Massachusetts, USA: Morgan Kaufmann.

Hasler, B. S., Kersten, B., \& Sweller, J. (2007). Learner control, cognitive load and instructional animation. Applied cognitive psychology, 21(6), 713-729. https:// doi.org/10.1002/acp.1345

Hilbert, T. S., \& Renkl, A. (2009). Learning how to use a computer-based concept-mapping tool: Self-explaining examples helps. Computers in Human Behavior, 25(2), 267-274. https:/ / doi.org/10.1016/j.chb.2008.12.006

Kalyuga, S. (2005). Effects of prior knowledge on multimedia learning: Does expertise reverse and how to manage it? In EdMedia: World Conference on Educational Media and Technology, 2005(1), 3164-3171.

Kalyuga, S. (2007). Expertise reversal effect and its implications for learner-tailored instruction. Educational Psychology Review, 19(4), 509-539. https:/ / doi.org/10.1007/s10648-007-9054-3

Kalyuga, S. (2008). Relative effectiveness of animated and static diagrams: An effect of learner prior knowledge. Computers in Human Behavior, 24(3), 852-861. https:/ / doi.org/10.1016/j.chb.2007.02.018

Kalyuga, S., \& Sweller, J. (2004). Measuring knowledge to optimize cognitive load factors during instruction. Journal of Educational Psychology, 96(3), 558-568. https:/ / doi.org/10.1037/0022-0663.96.3.558

Kalyuga, S., Ayres, P., Chandler, P., \& Sweller, J. (2003). The expertise reversal effect. Educational Psychologist, 38(1), 23-31. https://doi.org/10.1207/S15326985EP3801_4

Leahy, W., \& Sweller, J. (2005). Interactions among the imagination, expertise reversal, and element interactivity effects. Journal of Experimental Psychology: Applied, 11(4), 266. https:/ / doi.org/10.1037/1076-898X.11.4.266 
Liu, P. L., Chen, C.J., \& Chang, Y.J. (2010). Effects of a computer-assisted concept mapping learning strategy on EFL college students' English reading comprehension. Computers $\mathcal{E}$ Education, 54(2), 436-445. https:/ / doi.org/10.1016/j.compedu.2009.08.027

Mayer, R. E. (1997). Multimedia learning: Are we asking the right questions? Educational psychologist, 32(1), 1-19. https:/ / doi.org/10.1207/s15326985ep3201_1

Mayer, R. E., \& Chandler, P. (2001). When learning is just a click away: Does simple user interaction foster deeper understanding of multimedia messages? Journal of educational psychology, 93(2), 390. https:/ / doi.org/10.1037/0022-0663.93.2.390

Mayer, R. E., \& Moreno, R. (2003). Nine ways to reduce cognitive load in multimedia learning. Educational psychologist, 38(1), 43-52. https:/ / doi.org/10.1207/S15326985EP3801_6

Novak, J. D. (1990). Concept maps and Vee diagrams: Two metacognitive tools to facilitate meaningful learning. Instructional science, 19(1), 29-52. https:/ / doi.org/10.1007/BF00377984

Novak, J. D., \& Gowin, D. B. (1984). Learning how to learn. Cambridge, UK: Cambridge University Press. https:/ / doi.org/10.1017/CBO9781139173469

Paivio, A. (1986). Mental representations: A dual coding approach: New York, USA: Oxford University Press.

Reisslein, J., Atkinson, R.K., Seeling, P., \& Reisslein, M. (2006). Encountering the expertise reversal effect with a computer-based environment on electrical circuit analysis. Learning and Instruction, 16(2), 92-103. https:/ / doi.org/10.1016/j.learninstruc.2006.02.008

Rey, G. D., \& Buchwald, F. (2011). The expertise reversal effect: Cognitive load and motivational explanations. Journal of Experimental Psychology: Applied, 17(1), 33. https:/ / doi.org/10.1037/a0022243

Scheiter, K., Fillisch, B., Krebs, M. C., Leber, J., Ploetzner, R., Renkl, A., \& Zimmermann, G. (2017). How to Design Adaptive Information Environments to Support Self-Regulated Learning with Multimedia. In Informational Environments (pp. 203-223). Springer, Cham. https:/ / doi.org/10.1007/978-3-319-64274-1_9

Soellner, R., Lenartz, N., \& Rudinger, G. (2017). Concept mapping as an approach for expert-guided model building: The example of health literacy. Evaluation and Program Planning, 60, 245-253. https://doi.org/10.1016/j.evalprogplan.2016.10.007

Spanjers, I. A. E., Van Gog, T., \& van Merriënboer, J. J. G. (2010). A theoretical analysis of how segmentation of dynamic visualizations optimizes students' learning. Educational Psychology Review, 22(4), 411-423. https:/ / doi.org/10.1007/s10648-010-9135-6

Spanjers, I. A. E., van Gog, T., Wouters, P., \& van Merriënboer, J. J. G. (2012). Explaining the segmentation effect in learning from animations: The role of pausing and temporal cueing. Computers $\mathcal{E}$ Education, 59(2), 274-280. https://doi.org/10.1016/j.compedu.2011.12.024

Spanjers, I. A. E., Wouters, P., Van Gog, T., \& Van Merriënboer, J. J. G. (2011). An expertise reversal effect of segmentation in learning from animated worked-out examples. Computers in Human Behavior, 27(1), 46-52. https:/ / doi.org/10.1016/j.chb.2010.05.011

Xiaojun, L. (2017). An improved clustering-based collaborative filtering recommendation algorithm. Cluster Computing, 1-8. https:/ / doi.org/10.1007/s10586-017-0807-6

\section{http://www.ejmste.com}

